\title{
Trends in Nursing Research on Life-Sustaining Treatment in South Korea after the Enforcement of the Act on Decisions on Life-Sustaining Treatment
}

\author{
Jun-Hwa Choi, Ph.D. Candidate and Eun-Suk Choi, Ph.D. \\ College of Nursing, Research Institute of Nursing Science, Kyungpook National University, Daegu, Korea
}

Purpose: This study investigated trends of nursing research on life-sustaining treatment in South Korea. Methods: The period for data search was set from January 2018 to December 2020. The major search terms used were advance directives and life-sustaining treatment. Of the 492 records identified in the initial search, 461 articles were excluded for various reasons. A total of 31 records were included in the final qualitative analysis. Results: Sixteen studies had nursing students as study subjects, while nine studies had nurses as study subjects. The majority of the studies employed cross-sectional descriptive surveys as their research design. The major themes that emerged from the studies were as follows: attitudes toward withdrawal of life-sustaining treatment, knowledge of and attitudes toward advance directives, perceptions of a good death, and nurses' attitude toward life support care. Most of the studies reviewed concluded that attitudes toward withdrawal of life-sustaining treatment significantly impacted both knowledge of and attitudes toward advance directives and perceptions of a good death. Conclusion: To date, Korea still lacks extensive nursing research concerning life support care. Further research is needed to provide systematic education for nursing ethics and life support care, as well as the introduction of a specialist course. Furthermore, a multidisciplinary approach is necessary to provide diverse support systems and policy measures. In particular, since nurses are directly responsible for providing life support care, nurses' roles should be expanded in accordance with the Act on Decisions on Life-Sustaining Treatment.

Key Words: Life support care, Advance directives, Nursing research

Received October 14, 2021

Revised December 22, 2021

Accepted December 22, 2021

\section{INTRODUCTION}

As the human lifespan has been extended, there have been controversies in medicine on life-sustaining treatment due to issues related to human dignity and ethical considerations [1]. In 1997 at Boramae Hospital, a guardian requested discharge of a patient kept alive on a ventilator for economic reasons [2]. In this case, the patient died after a ventilator was removed upon the request of the guardian who signed a pledge not to raise any legal issues, and medical professionals were charged with aiding murder. In 2008, guardians requested discontinuation of life-sustaining treatment for an individual known as Grandmother Kim, who suddenly lost consciousness and entered a vegetative state during a lung cancer test, which led to a judgment permitting death with dignity [2].

Based on these cases, a social consensus on meaningless life- 
sustaining treatment gradually emerged, and active discussions were held about withdrawal of life-sustaining treatment as the need for evidence to help with rational decision-making on life-sustaining treatment increased [3]. Accordingly, the Act on Hospice and Palliative Care and Decisions on Life-Sustaining Treatment for Patients at the End of Life (hereinafter referred to as the Act on Decisions on Life-Sustaining Treatment) was enacted and a life-sustaining treatment decision system was implemented starting on February 4, 2018 [4].

According to the Article 2 Paragraph 4 of the Act on Decisions on Life-Sustaining Treatment, life-sustaining treatment means "medical treatment by cardiopulmonary resuscitation, hemodialysis, administering anticancer drugs, mechanical ventilation, etc. to a patient at the end of life, as prescribed by Presidential Decree, which only prolongs the process of dying without curative effect" [4].

Three years have passed since the enforcement of the Act on Decisions on Life-Sustaining Treatment, and there is still a fundamental limit on ensuring patients' death with dignity. However, efforts are continuing to be made to improve detailed operational aspects of the Act on Decisions on LifeSustaining Treatment [5], and, due to these legal changes, social perceptions on life-sustaining treatment are gradually changing.

In order to maintain a patient's end-of-life quality of life, the decision on life-sustaining treatment is a crucial factor [6]. In addition, withdrawal of life-sustaining treatment has significant benefits for both patients and their families in terms of reducing stress and the family's burden and guilt, as well as obviating the need to decide upon life-sustaining treatment in a time of crisis [7].

The role of medical professionals in caring for terminal $\mathrm{pa}^{-}$ tients is important. In particular, since nurses are in direct charge of end-of-life care, choices regarding life-sustaining treatment can have an important effect on end-of-life care provided to patients [8]. Nurses are in a key position to set standards for values about life-sustaining treatment, help patients' decision-making by preparing for patients' last moments as an advocate for patients, protect patients' autonomy and rights, and play a role as counselors and mediators [9].

Therefore, with the emerging role of nurses and the necessity of nursing care in relation to life-sustaining treatment, domes- tic research on life-sustaining treatment can suggest practical improvements in the field, system-level changes, and alternatives to policies. Research on these issues can also contribute to the development of research and practice by identifying deficiencies.

In other countries where reforms related to life-sustaining treatment were first implemented, extensive research is being conducted on the development of programs related to the withdrawal of life-sustaining treatment, interventions related to the decision to withdraw life-sustaining treatment, the role of caregivers in life-sustaining treatment, euthanasia, and decisions to withdraw life-sustaining treatment.

This study aimed to identify trends in domestic nursing research on life-sustaining treatment after the enactment of the Act on Decisions on Life-Sustaining Treatment in February 2018. Furthermore, this study is expected to provide basic data to suggest directions for future follow-up nursing research.

\section{METHODS}

\section{Study design}

This study is a secondary analysis of trends in domestic nursing research on life-sustaining treatment from February 2018, when the Act on Decisions on Life-Sustaining Treatment entered into force, to December 2020.

\section{Literature search}

Data were collected from January 2021 to March 2021, and approval from the institutional review board of $S$ Hospital (PSSH0475-202110-HR-019-01), with which the author was affiliated, was obtained before conducting the study. The data were searched and collected from February 2018 to December 2020 using domestic databases: Research Information Sharing Service (RISS), Data Base Periodical Information Academic (DBPIA), and Korean Studies Information Service System (KISS). The data included all domestic research articles on nursing and research articles $\mathrm{co}^{-}$-authored by nursing researchers among non-nursing journals. If dissertations were published in academic journals, the journal articles were included. The search keyword was "life-sustaining treatment." Additionally, "advance directives" and "withdrawal of life- 
sustaining treatment," which were topic words and similar words to the search keyword, were included in the literature search of domestic online databases to avoid missing potentially relevant articles.

\section{Literature selection}

The inclusion criteria were quantitative, qualitative, and mixed studies on life-sustaining treatment from February 2018 to December 2020. The exclusion criteria were (1) duplicates, (2) articles not related to nursing, (3) articles presented at conferences or symposia, (4) articles with a study period before February 2018, and (5) articles not on life-sustaining treatment.

Studies were selected from domestic online databases. The first database search identified 492 articles in total (66 articles from KISS, 154 articles from DBPIA, and 272 articles from RISS). Among these, 371 articles not related to nursing were excluded. The remaining articles were reviewed by the selection criteria based on their abstracts and main texts. Two articles presented at conferences or symposia, 66 duplicate articles, 20 articles with a study period before February 2018, and 2 articles not related to life-sustaining treatment were additionally excluded. Finally, 31 out of 492 articles were selected. During the literature selection, the information of each article was summarized in terms of the author(s), published year, study participants and design, study tools, and study results. The literature selection process was performed by two

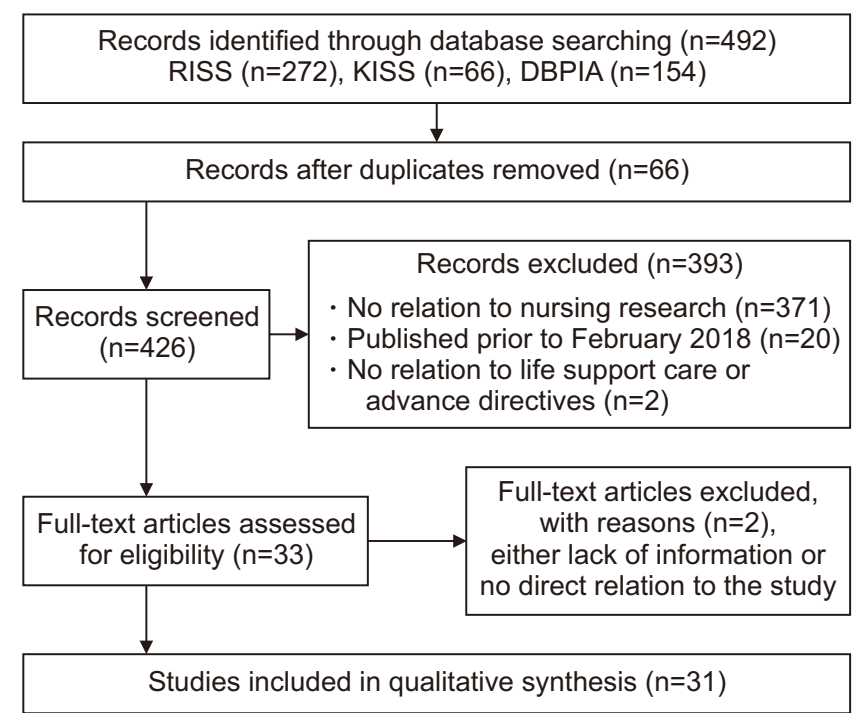

Figure 1. Study flow diagram of the review. researchers independently, and the researchers chose whether to select a study after a thorough discussion if they had different opinions (Figure 1).

\section{RESULTS}

\section{Methods of the included studies}

The general characteristics of the 31 included studies were presented in Table 1. The numbers of domestic nursing research by year on life-sustaining treatment were 1 in 2018, 14 in 2019, and 16 in 2020, respectively, and most articles were published in 2020 (51.6\%). The numbers of studies conducted at hospitals, in regional communities, and at schools were 13 (including 1 long-term care hospital), 4, and 14 (including 1 middle and high school), respectively. The numbers of studies in which the participants were nurses, nursing and medical students, adults, older adults, adolescents, hospital workers, and cancer patients were 9, 14, 2, 2, 1, 1, and 2, respectively. The most frequent participants were nursing and medical students, who were participants in 14 articles (45.2\%). The numbers of articles with sample sizes of less than 100 ,

Table 1. Characteristics of the Included Studies ( $N=31)$.

\begin{tabular}{llc}
\hline Characteristics & \multicolumn{1}{c}{ Categories } & $\mathrm{n}(\%)$ \\
\hline Publication year & 2018 & $1(3.2)$ \\
& 2019 & $14(45.2)$ \\
& 2020 & $16(51.6)$ \\
Study location & Hospitals and long-term care hospitals & $13(41.9)$ \\
& Communities & $4(12.9)$ \\
& Schools & $14(45.2)$ \\
Participants & Nurses & $9(29.0)$ \\
& Nursing students and medical students & $14(45.2)$ \\
& Adults and pre-elderly & $2(6.5)$ \\
& Elderly & $2(6.5)$ \\
& Adolescents & $1(3.2)$ \\
& Hospital workers & $1(3.2)$ \\
& Cancer patients & $2(6.5)$ \\
Sample size & $100>$ & $4(12.9)$ \\
& 100 200 & $15(48.4)$ \\
& 201 300 & $11(35.5)$ \\
& $>300$ & $1(3.2)$ \\
Qualitative studies & Q-methodology & $1(3.2)$ \\
& Phenomenology & $28(90.3)$ \\
& & $1(3.2)$ \\
& Non-experimental studies & $1(3.2)$ \\
\hline
\end{tabular}


100 200, 201 300, and more than 300 were 4, 15, 11, and 1, respectively, and almost half of the studies had a sample size between 100 to 200 (15 articles, 48.4\%). Twenty-nine articles were quantitative studies ( 1 experimental study, 28 descriptive studies). There were 2 qualitative studies (1 article using Q methodology, and 1 phenomenological study). Quantitative research was most frequently conducted using descriptive study designs, with 28 articles (90.3\%).

Table 2 presents the characteristics of the tools used in 29 quantitative studies, excluding 2 qualitative studies. Most of them were on knowledge, attitudes, and awareness regarding life-sustaining treatment or withdrawal of life-sustaining treatment. Most tools used were revised and supplemented by changing the participants or the terminology of the original tools developed by domestic or foreign researchers, or some of the questions were extracted. The reliability, as shown by Cronbach's $\alpha$, was $0.60 \sim 0.96$. There were $13,13,11$, and 8 articles using tools on knowledge of advance directives, attitudes toward withdrawal of life-sustaining treatment, perceptions of a good death, and attitudes toward advance directives, respectively.

Table 2. Instruments Used in the Included Studies ( $N=31$ ).

\begin{tabular}{|c|c|}
\hline Instruments & Studies \\
\hline Advance directive knowledge & A10, A14, A16, A17, A18, A24, A25, A28, A8, A15, A19, A21, A26 \\
\hline Advance directive attitude & $\mathrm{A} 15, \mathrm{~A} 16, \mathrm{~A} 17, \mathrm{~A} 18, \mathrm{~A} 22, \mathrm{~A} 24, \mathrm{~A} 25, \mathrm{~A} 26$ \\
\hline Advance directive writing intention & A25 \\
\hline Perceptions of a good death & $\mathrm{A} 1, \mathrm{~A} 2, \mathrm{~A} 5, \mathrm{~A} 7, \mathrm{~A} 14, \mathrm{~A} 22, \mathrm{~A} 26, \mathrm{~A} 27, \mathrm{~A} 28 \mathrm{~A} 8, \mathrm{~A} 19$ \\
\hline Perceptions of life-sustaining treatment decisions & A27 \\
\hline Terminal care attitude & A26, A27 \\
\hline Meaning of life & A1 \\
\hline Attitudes toward withdrawal of life-sustaining treatment & $A 1, A 2, A 4, A 5, A 7, A 9, A 10, A 11, A 17, A 3, A 6, A 8, A 12$ \\
\hline Perception of patients' rights & A7 \\
\hline Attitude toward euthanasia & A5 \\
\hline End-of-life care performance & A28 \\
\hline Nursing stress related to life-sustaining & A9, A28 \\
\hline Preference in care near the end of life & A29 \\
\hline Preparation for death & A29 \\
\hline Anxiety regarding death & $\mathrm{A} 11, \mathrm{~A} 20, \mathrm{~A} 23, \mathrm{~A} 29$ \\
\hline Respect for life & $\mathrm{A} 4, \mathrm{~A} 12$ \\
\hline Attitude to death & $\mathrm{A} 2, \mathrm{~A} 4, \mathrm{~A} 8$ \\
\hline Selfesteem & A4, A15 \\
\hline Death acceptance & A11 \\
\hline Dignified death attitudes & $\mathrm{A} 23, \mathrm{~A} 24$ \\
\hline Ego integrity & A10 \\
\hline Hospice perception & A15, A16 \\
\hline Knowledge of medical interventions after the discontinuation of life-sustaining care & A17 \\
\hline Ethics values & A18 \\
\hline Moral sensitivity & $A 3, A 8, A 22$ \\
\hline Consciousness of biomedical ethics & A3, A22 \\
\hline Awareness toward withdrawal of life-sustaining treatment & A20 \\
\hline Knowledge of end-of-life care, life-sustaining treatment, and advance directive & A21 \\
\hline Educational needs regarding advance directives & A21 \\
\hline Knowledge of organ donation and transplantation & A13 \\
\hline Attitude of organ donation and transplantation & A13 \\
\hline Awareness of death & A13 \\
\hline Knowledge and perceptions of hospice palliative care & A13 \\
\hline Role perception & A9 \\
\hline
\end{tabular}




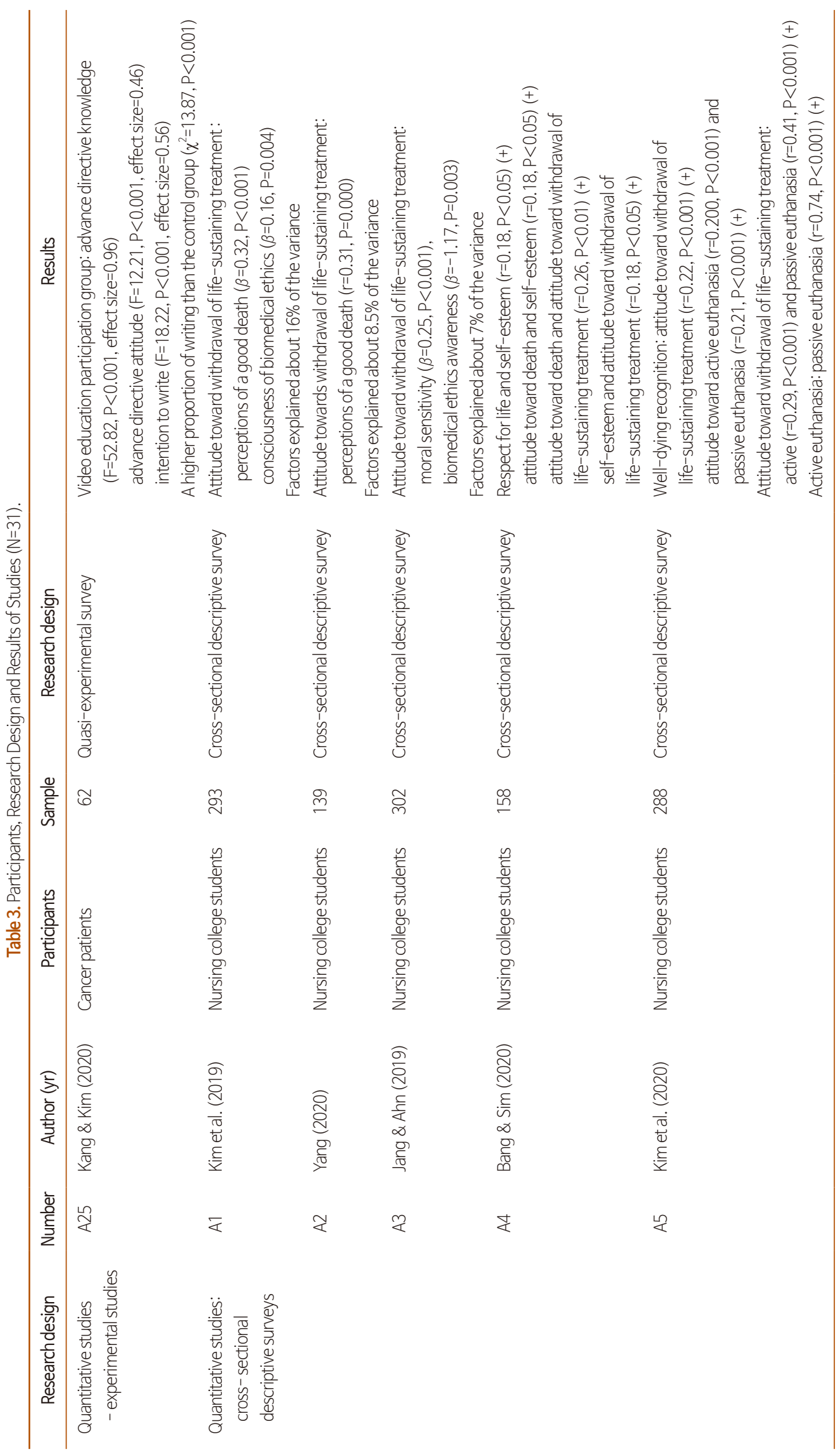




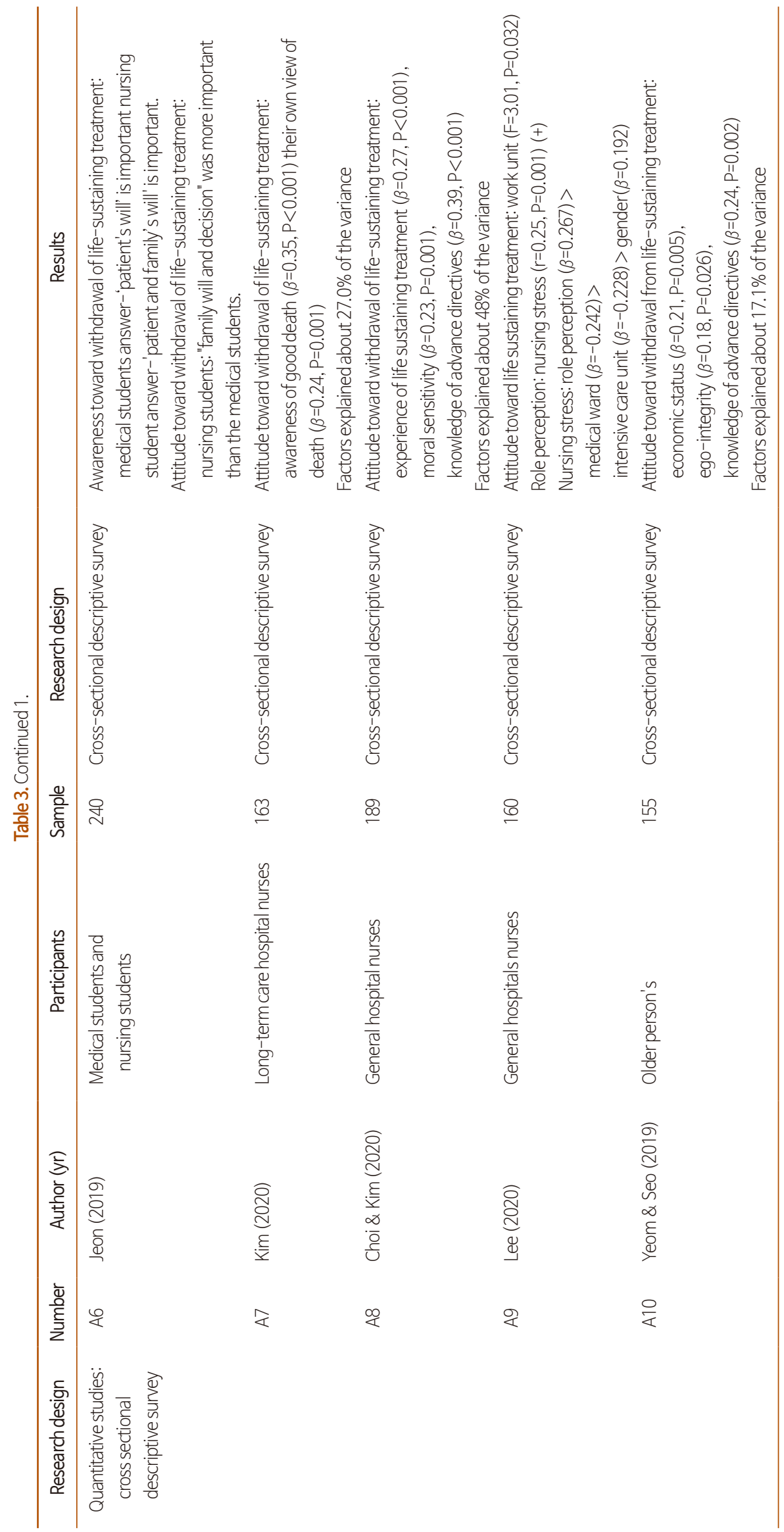




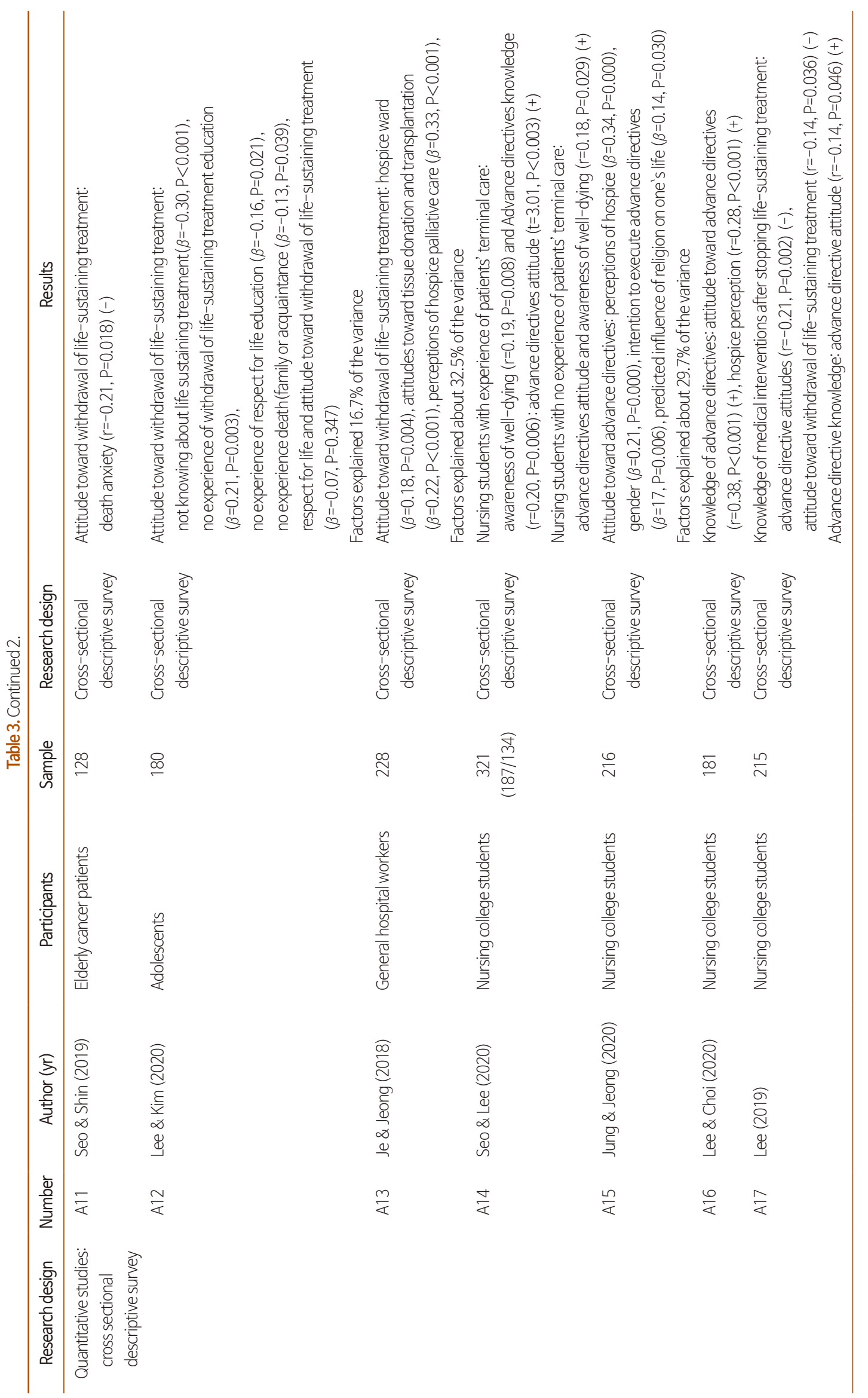




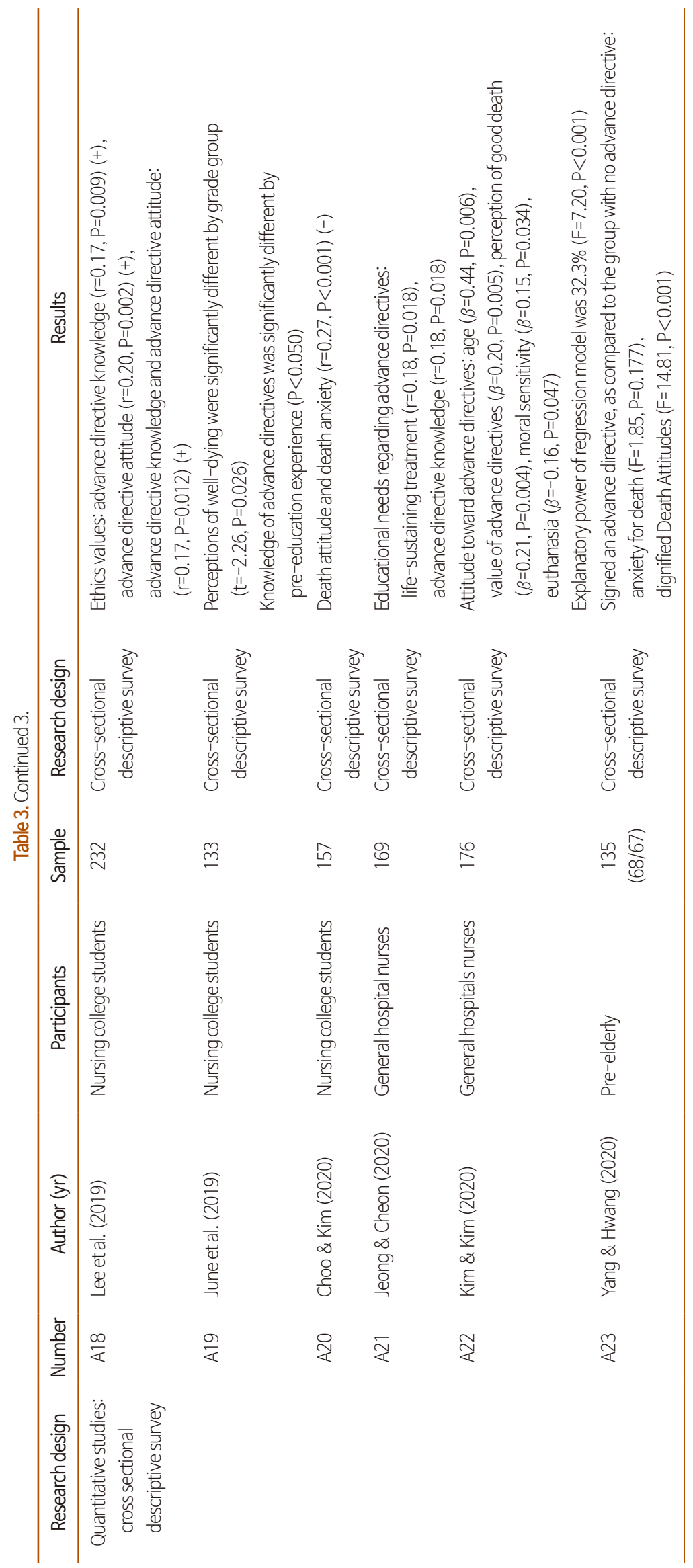




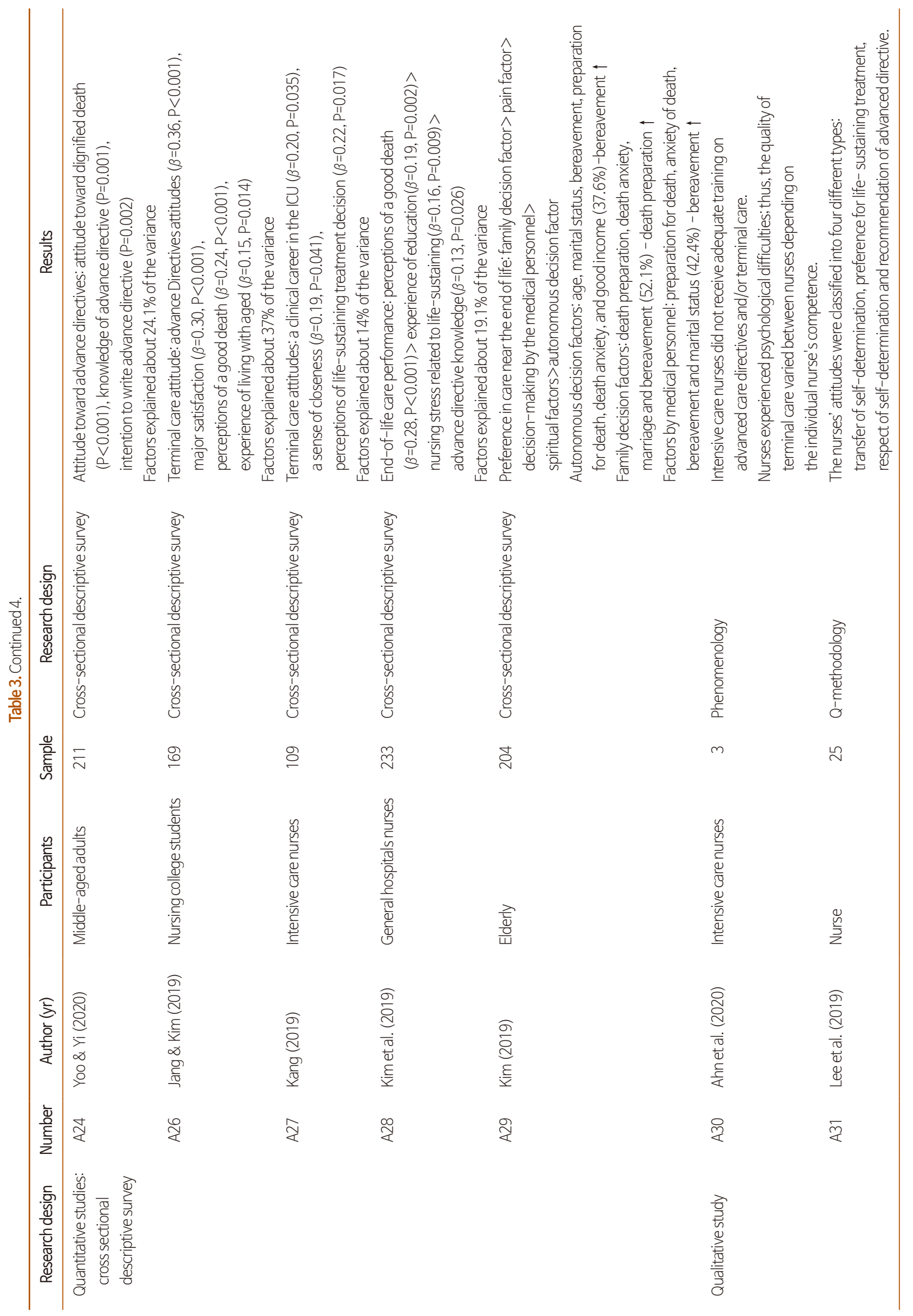




\section{Attitudes toward withdrawal of life-sustaining treatment and perceptions of a good death (Table 3)}

The studies conducted on attitudes toward withdrawal of life-sustaining treatment among nursing college students showed that consciousness of consciousness of biomedical ethics and a good death were correlated with attitudes toward withdrawal of life-sustaining treatment [A1,A2]. Moral sensitivity [A3], self-esteem, and attitudes toward dying were correlated with attitudes toward withdrawal of life-sustaining treatment [A4]. Active and passive euthanasia were also correlated with attitudes toward withdrawal of life-sustaining treatment [A5]. Medical students mostly supported patients' choice and patient-centered decision-making on withdrawal of life-sustaining treatment in terms of awareness and attitudes of withdrawing life-sustaining treatment, while nursing students' attitudes focused on the importance of choice and decision-making by the families as well of patients [A6]. The awareness of a good death and value on death influenced attitudes toward withdrawal of life-sustaining treatment in nurses in long-term care hospitals [A7]. Attitudes toward withdrawal of life-sustaining treatment of nurses were correlated with moral sensitivity, knowledge of advance directives, and perceptions of a good death [A8] and were significantly different according to wards [A9]. Ego-integrity, knowledge of advance directives, and economic status significantly affected attitudes toward withdrawal of life-sustaining treatment of older adults [A10]. Attitudes toward withdrawal of life-sustaining treatment were not statistically correlated with death acceptance, but were significantly correlated with death anxiety. Higher positive attitudes toward withdrawal of lifesustaining treatment were associated with lower death anxiety [A11]. In a study on adolescents, bioethics had no effect on attitudes toward withdrawal of life-sustaining, but personal experience such as awareness of life-sustaining treatment, having experienced education on withdrawing life-sustaining treatment, having experienced education on life respect, and having experienced death of family members or acquaintances had an effect on attitudes toward withdrawal of life-sustaining treatment [A12]. In a study on hospital workers, working in a hospice ward, attitudes toward donation of human organs and transplants, and awareness of hospice and palliative care were significantly associated with attitudes toward withdrawal of life-sustaining treatment [A13].

\section{Knowledge and attitudes toward advance directives (Table 3)}

There were no differences in knowledge of advance directives and well-dying between nursing students who had observed end-of-life care and those who had not. Nursing students who had observed end-of-life care had more positive attitudes toward advance directives than those who had not [A14]. The factors affecting attitudes toward advance directives were awareness of hospice, gender, preparation of advance directives, and the impact of religion on life [A15]. Knowledge on advance directives was correlated with attitudes toward advance directives and awareness of hospice [A16,A17] as well as ethical values [A18]. In addition, knowledge of advance directives was significantly higher in third- and fourthyear nursing students than in first- and second-year nursing students, and was significantly different according to the experience of prior education [A19]. There was a significant correlation between death attitude and death anxiety, but no correlation between those variables and knowledge of advance directives. There was a significant difference between nursing students' age and the completion of hospice education [A20]. In a study on nurses' educational need on advance directives, a higher knowledge level on life-sustaining treatment and advance directives was associated with a higher educational need [A21]. Knowledge about advance directives was confirmed as the factor with the strongest effect on attitudes toward withdrawal of life-sustaining treatment [A8]. The factors affecting attitudes towards advance directives were awareness of a good death, euthanasia (a subdomain of consciousness of biomedical ethics), and moral sensitivity [A22]. Death anxiety did not show a significant difference between people who wrote advance directives and those who did not in a study on preelderly individuals. The pre-elderly who wrote advance directives had higher scores for attitudes toward dignified death than those who did not [A23]. The factors affecting attitudes toward advance directives were death with dignity, knowledge of advance directives, and willingness to write advance directives, and the most important factor was attitudes toward 
death with dignity [A24]. A study conducted among cancer patients that explored education using videos to promote an understanding of advance directives found that intervention led to positive attitude changes, increasing participants' willingness to write advance directives, which could contribute to a greater understanding of life-sustaining treatment and selfdecision [A25].

\section{Attitudes toward end-of-life care and performance (Table 3)}

More favorable attitudes toward end-of-life care among nursing students were associated with more favorable attitudes toward advance directives, higher satisfaction with their major, more positive attitudes toward a good death, and experience of living with older adults. In particular, attitudes toward advance directives were identified as a predictor of end-oflife care [A26]. In a study on nurses, nurses in intensive care units with more career experience, higher intimacy, and higher awareness toward decisions on life-sustaining treatment showed more positive attitudes toward end-of-life care [A27]. The major predictors affecting end-of-life care performance were perceptions of a good death, having experienced education on life-sustaining treatment, nursing stress related to lifesustaining treatment, and knowledge of advance directives, in descending order [A28]. The factors affecting nursing stress related to life-sustaining treatment were gender, working in an internal medicine ward, working in an intensive care unit, and role perception [A9].

\section{Other study results (Table 3 )}

A study on older adults investigating the relationships among death anxiety, death preparation, and preference for end-oflife care showed that preference for end-of-life care was correlated with death anxiety and death preparation, and artificial extension of life was the least preferable. The most important factor was family, followed in descending order by medical professionals, and spirituality. Death preparation, death anxiety, age, marital status, and income level were also significant influencing factors [A29].

In a phenomenological study, nurses in the intensive care unit had no opportunity to receive education on decision-making on life-sustaining treatment and end-of-life care, experi- enced psychological conflict, and performed end-of-life care differently depending on personal competence [A30]. In a Q methodology study, nurses' attitudes toward life-sustaining treatment were classified into 4 types: type I ('transfer of selfdetermination'), type 2 (preference for life extension treatment'), type 3 ('respect of self-determination'), and type 4 ('recommendation of advance directives'). Type 4 ('recommendation of advance directives') appeared for the first time after the Act on Decisions on Life-Sustaining Treatment entered into force, and it was differentiated type compared to those that appeared in previous studies. Nurses with this type of attitude (i.e., with desirable attitudes toward life-sustaining treatment as medical professionals) would contribute positively to the proliferation of advance directives in society [A31].

\section{DISCUSSION}

This study identified trends in domestic nursing research after February 2018 when the Act on Decisions on Life-Sustaining Treatment entered into force. Although the inclusion of 31 studies can be interpreted as indicating a lack of domestic nursing research after the Act on Decisions on Life-Sustaining Treatment, the number of studies steadily increased from year to year.

The most frequent study participants were nursing students. This is because nursing students, as future nurses, can have an appropriate knowledge of advance directives and positive attitudes toward them at this time of increasing social interest with the legal implementation of advance directives [9].

Meanwhile, studies on nurses were not actively conducted. Scherer et al. [10] reported that care from nurses who provided 24-hour nursing at patients' sides had important effects on decision-making and attitudes of patients and caregivers. Although nurses by themselves are aware that they should participate actively in decision-making on life-sustaining treatment, since they are in close contact with patients more than anyone else and understand the needs of patients and doctors most, research on this issue is not being conducted, most likely due to nurses' busy workloads.

There were studies on adults, adolescents, older adults, and hospital workers, but it was difficult to access these groups from an ethical perspective before the Act on Decisions and 
Life-Sustaining Treatment. Since the implementation of the Act can facilitate approaches from an ethical perspective, it is necessary to conduct research using various methods (e.g., $\mathrm{co}^{-}$ hort or experimental studies) [11] and participants by obtaining sufficient samples.

There were 2 qualitative studies and 29 descriptive quantitative studies, indicating that the research in this field needs to be diversified in terms of study design.

The most frequently used tools dealt with attitudes toward withdrawal of life-sustaining treatment, perceptions of a good death, knowledge and attitudes toward advance directives, and attitudes toward end-of-life care and performance of end-oflife care.

Attitudes toward withdrawal of life-sustaining treatment had effects on consciousness of biomedical ethics and perceptions of a good death in studies on nurses and nursing students. Previous results reported conflicting results according to which consciousness of biomedical ethics had no effect on attitudes toward withdrawal of life-sustaining treatment. However, studies reporting that perceptions of a good death had an effect on attitudes toward withdrawal of life-sustaining treatment showed similar results [9]. A study on nursing students also found that consciousness of biomedical ethics was affected by attitudes toward withdrawal of life-sustaining treatment [12]. However, there was a conflicting study [13] on nurses, which found that perceptions of a good death were not positively correlated with attitudes toward withdrawal of life-sustaining treatment. This discrepancy may have occurred because the study was conducted when even medical professionals were not widely aware of the concept of life-sustaining treatment.

In a study on older adults, attitudes toward withdrawal of life-sustaining treatment had effects on the ego-integrity, knowledge of advance directives, and economic status. Attitudes toward withdrawal of life-sustaining treatment were correlated with death anxiety in a study conducted among patients, and more positive attitudes toward withdrawal of lifesustaining treatment were associated with lower death anxiety. A previous study showed similar results that attitudes toward withdrawal of life-sustaining treatment were positive in people with higher knowledge of advance directives and higher egointegrity, as well as in older adults with good economic status and good health [8].
Patient-centered decision-making on withdrawal of lifesustaining treatment was an important factor for medical students, while nursing students focused on the importance of choices made by family members as well as by patients.

In a study on adolescents, consciousness of biomedical ethics did not affect attitudes toward withdrawal of life-sustaining treatment. However, it was reported that personal experience, such as awareness of life-sustaining treatment, having experienced education on withdrawing life-sustaining treatment, having experienced education on life respect, and having experienced the death of family members or acquaintances had an effect on attitudes toward withdrawal of life-sustaining treatment [14]. A direct comparison was not possible since there were no previous studies on nursing students, medical students, and adolescents.

A study showed that nursing students' perceptions of a good death had an effect on attitudes toward withdrawal of lifesustaining treatment. There was no difference in perceptions of a good death and knowledge of advance directives between nursing students who had observed end-of-life care and those who had not. A previous study showed similar results that nursing students' perceptions of a good death had a significant effect on their attitudes toward withdrawal of life-sustaining treatment [9].

Preparation of advance directives was a factor affecting attitudes toward advance directives, and higher knowledge level was associated with higher educational needs for advance directives. Knowledge of advance directives was the most important factor affecting attitudes toward withdrawal of lifesustaining treatment for nurses, and the factors affecting the attitudes toward advance directives were perceptions of a good death, consciousness of biomedical ethics, and moral sensitivity. A previous study showed similar results that higher knowledge of advance directives of nurses was significantly associated with higher confidence and educational needs [15].

A study conducted among nursing students found that knowledge of advance directives was correlated with attitudes toward advance directives, and knowledge of advance directives showed significant differences according to experience of prior education, age, and completion of hospice and palliative education. In previous studies, nursing students showed relatively positive attitudes toward advance directives [16] and 
attitudes toward advance directives were an important factor affecting end-of-life care [17]. In a study on patients, education using video enhanced the willingness to write advance directives, and pre-elderly patients who wrote advance directives had higher scores for attitudes toward dignified death than those who did not [18]. There were no previous studies after the Act on Decisions on Life-Sustaining Treatment entered into force in 2018 that would be directly comparable.

More positive attitudes toward advance directives of nursing students were associated with more favorable attitudes toward end-of-life care. Nurses in intensive care units with more career experience and higher awareness toward decisions on life-sustaining treatment showed more positive attitudes toward end-of-life care. According to a previous study, nurses in the intensive care unit had positive awareness of withdrawal of life-sustaining treatment. They placed higher importance on patient participation or respect for patients' opinions and objected to unilateral decision-making by medical professionals [19]. The predictors of end-of-life care performance were perceptions of a good death, having experienced education on life-sustaining treatment, nursing stress related to lifesustaining treatment, and knowledge of advance directives, in descending order. Moral sensitivity and work experience were factors affecting end-of-life care performance in a previous study [20].

In a qualitative study, 'recommendation of advance directives' among nurses newly appeared as a type of attitude toward life-sustaining treatment after the Act on Decisions on Life-Sustaining Treatment entered into force. In a phenomenological study, nurses in an intensive care unit had no opportunities to receive education on life-sustaining treatment and performed end-of-life care differently depending on personal competence. Efstathiou et al. [21] stated that lifesustaining treatment is a problem facing intensive care unit nurses and they should play a major role in life-sustaining treatment. Furthermore, job development in order to provide effective life-sustaining treatment including communication, patient- and family-centered decision-making, continuity of treatment, emotional and spiritual support, and support for medical professionals can improve life-sustaining treatment for critical patients and their families [21].

As shown in the results of domestic nursing research after the Act on Decisions on Life-Sustaining Treatment entered into force, nurses perform end-of-life care directly. In Japan, the US, and the UK, when a consensus of a patient and family cannot be reached, a palliative care team reaches a consensus through a separate committee, and nurses are the main personnel in the committee even though various occupations participate [22]. In addition, education experience, end-oflife experience, and completion of education on life-sustaining treatment had effects on nurses as well as nursing students, but they did not have an opportunity for education. Dowling et al. [7] investigated universal knowledge and lack of education on life-sustaining treatment in several countries, and stated that there are universally important barriers to implementation. The study is similar to domestic research in that it describes the level of occupational uncertainty on life-sustaining treatment.

A report of the Institute of Policy Studies in Singapore stated that although doctors and nurses were not prepared to deal with terminal patients only with the basic training they had received, the number of specialists was too small, and there was discomfort due to stigma and superstition, they should have skills to talk about death with patients [23].

Jack et al. [24] reported that education on advance care planning enhanced confidence in front-line medical professionals and prevented potential delays. Hussin et al. [25] also stated that it was necessary to improve the level of professionalism, training, knowledge, and attitudes of nurses in order to improve the quality of life-sustaining treatment. Therefore, a systematic curriculum and expert courses [26] that incorporate life-sustaining treatment into the curriculum of nursing ethics, geriatric nursing, oncology nursing, and hospice palliative nursing should be introduced so that nursing students, nurses, and specialized nurses can recognize the withdrawal of lifesustaining treatment as a good death.

In South Korea, the current life-sustaining treatment decision form is completed based on the judgment of two doctors. In US and Canada, nurses judge and write a form on terminal patients without a doctor's signature, and nurses are also working as clinical ethics consultants [23]. Dowling et al. [7] also emphasized the main role of nurses in authorizing patients to express their will and preferences, supporting patients' abilities to decide upon their treatments, initiating end-of-life care discussions early, and advocating for the recognition of 
advance care guidelines. Therefore, in South Korea as well, the role of nurses should be expanded through a proper arrangement of nursing personnel, the development of nursing fees for life-sustaining treatment, and the development of end-of-life care performance and life-sustaining treatment guidelines.

As Hue et al. [27] reported that the rate of end-of-life patients using intensive care units decreased by $10 \%$ as a result of support for palliative medical service in hospitals in the US, introducing palliative care service programs can be a way to improve the quality of end-of-life care. In South Korea, it is necessary to develop service programs for palliative care at palliative care centers and medical institutions through multidisciplinary collaboration, as well as to prepare various types of institutional systems and support.

It is also required to review patients' wills on emergencies and advance care, and this will be a task that South Korea needs to address in the future. Furthermore, since education and promotion using videos for patients and promotion of withdrawal of life-sustaining treatment for the general public shape attitudes toward perceptions of a good death, proactive promotion of withdrawal of life-sustaining treatment through various media is necessary.

Lastly, with the enforcement of the Act on Decisions on LifeSustaining Treatment, interest and awareness of withdrawal of life-sustaining treatment have increased in accordance with the purpose of the act to promote human dignity and comfortable death. According to trends in domestic nursing research, nursing ethics education, systematic education, and expert courses on life-sustaining treatment should be introduced. In addition, various support and systematic plans should be prepared through the development of guidelines and programs on lifesustaining treatment, sharing other countries' cases including palliative service centers other than medical institutions, research of various types, and a multidisciplinary approach. In particular, nurses' roles should be expanded in order to respond proactively to environmental changes in life-sustaining treatment. This study is significant in that it identifies the current status of domestic nursing research after the enforcement of the Act on Decisions on Life-Sustaining Treatment and suggests directions for future research. However, there is a possibility that unpublished studies were excluded since studies were searched using online databases. There is also a limitation in interpreting the results, since this study only included domestic nursing studies after the Act on Decisions on LifeSustaining Treatment entered into force. As nursing research on life-sustaining treatment is still lacking in South Korea, an expanded study including nursing research from other countries should be conducted. In addition, studies using text network analyses are suggested in the future.

\section{CONFLICT OF INTEREST}

No potential conflict of interest relevant to this article was reported.

\section{ORCID}

Jun-Hwa Choi, https://orcid.org/0000-0002-5907-4878

Eun-Suk Choi, https://orcid.org/0000-0002-4622-745X

\section{AUTHOR'S CONTRIBUTIONS}

Conception or design of the work: all authors. Data collection: JHC. Data analysis and interpretation: JHC. Drafting the article: JHC. Critical revision of the article: all authors. Final approval of the version to be published: all authors.

\section{SUPPLEMENTARY MATERIALS}

Supplementary materials can be found via https://doi. org/10.14475/jhpc.2022.25.1.25.

\section{REFERENCES}

1. Kim HS, Kim KA. Effects of perception of death, consciousness of biomedical ethics, and moral sensitivity on the attitude toward advance directives of clinical nurses. Health \& Nursing 2020;32:29-37. 
2. Choi JY, Jang SG, Kim CJ. Institutional ethics committees for decisions on life-sustaining treatment in Korea: their current state and experiences with their operation. Korean J Med Ethics 2019;22:209-33.

3. Policy \& legislations: overview [Internet]. Seoul: National Agency for Management of Life-Sustaining Treatment; 2019 [cited 2021 Jan 27 ]. Available from: https://www.1st.go.kr.

4. Life-sustaining treatment: Ministry of Health and Welfare [Internet]. Sejong: Korean Law Information Center; 2018 [cited 2021 Mar 7]. Available from: https://www.law.go.kr.

5. Ahn KJ, Kong BH, Song YJ. A study on the life-sustaining treatment decision-making and end-of-life care experiences of intensive care nurses after the enforcement of the life-sustaining treatment decision-making act. J Korean Bioethics Assoc 2020;21:31-53.

6. Kim MS. Factors affecting the attitude toward withdrawal of life-sustaining treatment of nurses working at long-term care hospitals. J Korean Acad Soc Nurs Educ 2020;26:383-92.

7. Dowling T, Kennedy S, Foran S. Implementing advance directives-an international literature review of important considerations for nurses. J Nurs Manag 2020;28:1177-90.

8. Choi EJ, Jeong HS. The effect of nursing students' consciousness of biomedical ethics, good death recognition, and self-esteem on the attitude toward withdrawal of life-sustaining treatment. JKAIS 2018;19:275-84.

9. Kim EY, Seo EH, Jung EY. Knowledge and attitudes toward the withdrawal of life-sustaining treatment among nursing students. J East-West Nurs Res 2017:23:1-8.

10. Scherer Y, Jezewski MA, Graves B, Wu YWB, BuX. Advance directives and end-of-life decision making survey of critical care nurses' knowledge, attitude, and experience. Critical Care Nurse 2006;26:30-40.

11. Cheon JY. Completion of advance directive and withdrawal of life-sustaining treatments among older adults in south Korea: a systematic review. J.KSLES 2020;27:473-88.

12. Kim EY. Effect of consciousness of biomedical ethics critical thinking disposition on attitude toward withdrawal of life-sustaining treatment among nursing students. Journal of Digital Convergence 2018;16:453-63.

13. Kim SN, Kim HJ. Recognition of good death, attitude towards the withdrawal of life-sustaining treatment, and attitude towards euthanasia in nurses. Korean J Hos Pallia Care 2016;19:136-44.

14. Lee IS, Kim KJ. Exploring the factors influencing attitudes toward withdrawal of life-sustaining treatment in adolescents. J Korean Acad Soc Home Care Nurs 2020;27:82-91.

15. Jang NS, Park HS, Kim MR, Lee JY, Cho YW, Kim KM, et al. Knowledge, confidence, and learning needs regarding advance directives among hospital nurses. J Korean Crit Care Nurs 2018;11:35-45.

16. Kwon KE, Yoo MS. Biomedical ethics awareness and attitudes toward dignified death and advance directives among nursing students. J Korean Acad Soc Home Care Nurs 2018;25:204-14.

17. Park EH, Kim NY. The influence of nursing professionalism, attitudes toward advance directive, and death anxiety on terminal care performance of nurses in long-term care hospitals. KJAN 2018;30:183-93.

18. Kang JS, Kim HO. The effect of video education on cancer patient advance directive writing. AON 2020;20:39-49.

19. Choi JY, Son YJ, Lee Kh. Attitudes, perceptions, and experiences toward end-of-life care decision-making among intensive care unit nurses in Korea. J Korean Crit Care Nurs 2020;13:27-43.

20. Lee JS, Ahn SH. The impact of moral sensitivity and moral distress on end-of-life care performance among intensive care unit nurses. Korean J Med Ethics 2019;22:140-60.

21. Efstathiou N, Clifford C. Clifford C. The critical care nurse's role in end-of-life care: issues and challenges. Nurs Crit Care 2011;16:116-23.

22. Choi EK, Hong JU, Kim MS, Keam BS, Kim MS, HEO DS et al. The decision-making process regarding life-sustaining treatment in four countries: Taiwan, Japan, the US, and the UK. Korean J Med Ethics 2017;20:131-51.

23. Institute of Policy Studies: Better life [Internet]. Singapore: SPH Media Limited, Co.; 2019 [cited 2021 Jun 6]. Available from: https://www. straitstimes.com/forum/letters-in-print/remove-some-of-the-barriers-to-end-of-life-planning.

24. Jack B, Kirton J, Kinloch K, O'brien M. Exploring the impact on front line staff of training in advance care planning. Nursing Times 2020;116:27-31.

25. Hussin EOD, Wong LP, Chong MC, Subramanian P. Factors associated with nurses' perceptions about quality of end-of-life care. Int Nurs Rev 2018:65:200-8.

26. Kwon KE. A study on the model of life-sustaining treatment decision making through shared decision making at the end of life. J Korean Bioethic Assoc 2019;20:45-61.

27. Hue M, Lu Y, Ma X, Morrison RS, Li G, Wunsch H. Association between the implementation of hospital-based palliative care and use of intensive care during terminal hospitalizations. JAMA Network Open 2020;3:e1918675. 


\section{Appendix 1. List of Studies Included in Review.}

1. Kim KN, Kang EH, Kim MY. Factors influencing on the attitude toward withdrawal of life-sustaining treatment of nursing college students. JKAIS 2019;20:429-37.

2. Yang SA. Factors influencing attitude toward withdrawal of life-sustaining treatment among nursing students. JCIT 2020;10:226-35.

3. Jang YM, Ahn EK. The effects of moral sensitivity, biomedical ethics awareness on attitudes toward withdrawal of life-sustaining treatment of nursing students. Journal of Industrial Convergence 2019;17:53-61.

4. Bang MR, Sim SS. The relationship among respect for life, attitude to death, self esteem and attitude toward withdrawal of life-sustaining treatment of nursing students. KALCl 2020;20:457-72.

5. Kim MJ. Nursing students awareness of well-dying, attitude toward withdrawal of life-sustaining treatment and attitude toward euthanasia. Journal of Industrial Convergence 2020;18:51-9.

6. Jeon JH. Difference between medical students and nursing students about awareness and attitude toward withdrawal of life-sustaining medical treatment. Journal of the Korea Convergence Society 2019;10:335-44.

7. Kim MS. Factors affecting the attitude toward withdrawal of life-sustaining treatment of nurses working at long-term care hospitals. J Korean Acad Soc Nurs Educ 2020;26:383-92.

8. Choi SY, Kim KH. The influence of moral sensitivity, knowledge of advanced directives, good death perception on nurses' attitudes toward the withdrawal of life-sustaining treatment in a general hospital. Korean J Rehabil Nurs 2020;23:120-31.

9. Lee MR. Attitude, Role perception and nursing stress on life sustaining treatment of nurses. Journal of Digital Convergence 2020;18:347-55.

10. Yeom EY, Seo KS. Influence of older person's ego integrity and knowledge of advance directives on their attitude toward withdrawal from life-sustaining treatment. J Korean Gerontol Nurs 2019;21:173-82.

11. Seo YM, Shin SJ. The relationship among attitudes toward the withdrawal of life-sustaining treatment, death anxiety, and death acceptance among hospitalized elderly cancer patients. AON 2019;19:142-9.

12. Lee IS, Kim KJ. Exploring the factors influencing attitudes toward withdrawal of life-sustaining treatment in adolescents. J Korean Acad Soc Home Care Nurs 2020;27:82-91.

13. Je NJ, Jeong SH. Factors influencing withdrawal of life-sustaining treatment in tertiary general hospital workers-knowledge and attitude of organ donation and transplantation, awareness of death, knowledge and perception of hospice palliative care. Korean J Hos Pallia Care 2018;21:92-103.

14. Seo YH, Lee HJ. A comparison of awareness to well-dying, knowledge and attitudes toward advance directives of nursing students according to terminal care experience. KOCS 2020;37:1430-40.

15. Jung MR, Jeong E. Effects of perception on hospice, self-esteem, knowledge on advance directives in nursing student on attitudes toward advance directives. Journal of Digital Convergence 2019;17:255-64.

16. Lee KJ, Choi YS. Nursing students' knowledge, attitudes to advance directives and hospice perception. Journal of KOEN 2020;14:181-90.

17. Lee YH. Nursing students knowledge, attitudes to life-sustaining and advance medical directives. The Journal of Humanities and Social science 2019;10:723-37.

18. Lee HJ, Ha JH, Yun JM. Nursing students' knowledge, attitudes to advance medical directives and ethics values. JKANA 2019;25:282-91.

19. June KJ, Jeong SH, Ahn HJ, Hong YK, Lee YJ, Kim YA, et al. Nursing students' perception of well-dying and knowledge for advanced directives. J Korean Acad Rural Health Nurs 2019;14:1-7.

20. $\mathrm{H}$, Kim EH. Death attitude, death anxiety and knowledge toward advance directives among nursing students. J Korean Pubilc Health Nurs 2020;34:211-24.

21. Jeong JH, Cheon JY. Relationship of knowledge of end-of-life care, life-sustaining treatment, and advance directive with the educational needs regarding advance directives writing among nurses in general hospital in convergence era. Journal of Internet of Things and Convergence 2020;6:45-53.

22. Kim HS, Kim KA. Effects of perception of death, consciousness of biomedical ethics, and moral sensitivity on the attitude toward advance directives of clinical nurses. Health \& Nursing 2020;32:29-37.

23. Yang SM, Hwang EH. Death anxiety and dignified death attitudes of pre-elderly who opt for signing advance directives. J Korean Pubilc Health Nurs 2020;34:251-62.

24. Yoo, HI, Yi YH. Middle-aged adults' attitudes toward dignified death and advance directives, and knowledge of advance directives. J Korean Clin Nurs Res 2020;26:86-96.

25. Kang JS, Kim HO. The effect of video education on cancer patient advance directive writing. J Asian Oncol Nurs 2020;20:39-49.

26. Jang IS, Kim YJ. Effects of awareness to well-dying, knowledge and attitudes toward advance-directives on attitude toward end-of-life care in nursing students. Korean J Rehabil Nurs 2019;22:104-13.

27. Kang JH, Lee YM, Lee HJ. Effect of the awareness of a good death and perceptions of life-sustaining treatment decisions on attitudes of intensive care nurses toward terminal care. J Korean Crit Care Nurs 2019;12:39-49.

28. Kim SK, Kim SH, Yun HY. Factors that influence end-of-life care provided by nurses in general hospitals. Korean J Med Ethics 2019;22:5372. 
29. Kim AL. Influencing factors on the elderly's preference in care near the end of life focusing on preparation for death and anxiety for death. KSW 2019;14:113-23.

30. Ahn KJ, Kong BH, Song YJ. A study on the life-sustaining treatment decision-making and end-of-life care experiences of intensive care nurses after the enforcement of the life-sustaining treatment decision-making act. J Korean Bioethics Assoc 2020;21:31-53.

31. Lee GN, Yong JH, Jung Y, Lee HJ. Nurses' attitudes toward life sustaining medical treatment. KMHS 2019;12:31-8. 